\title{
Neurolinguistic analysis of a case of phonological alexia in Arabic language
}

\author{
Mohamed Taiebine ${ }^{1,3}$, Mustapha El Alaoui Faris ${ }^{1,2,3}$ \\ 'University Mohammed V. Faculty of Medicine and Pharmacy-Rabat; ${ }^{2}$ Department of Neurology A and Neuropsychology, Specialty Hospital, Souissi \\ Quarter-Rabat; ${ }^{3}$ Alzheimer's Center, Rabat, Morocco
}

\begin{abstract}
Cases of phonological alexia have been widely studied in various occidental languages, but to our knowledge no case has been reported in Arabic language. We report a neurolinguistic analysis of a single case of phonological alexia in Arabic. AL, 48-year-old, right-handed man, who is a teacher of Arabic, at the age of 35 presented with hemiplegia and severe aphasia. A Cerebral Computed Tomography scan showed a wide left hemispheric infarct. As a result, he developed Broca's aphasia and alexia. A neurolinguistic analysis of reading was evaluated using the Arabic Dyslexia-Dysgraphia Battery which consists of a corpus of 331 words with different parts of speech and reading task of non-words. The patient had much more difficulty reading non-words than words (90\% of errors versus $37 \%$ ). This is the classical dissociation that characterizes phonological alexia.
\end{abstract}

Keywords: Arabic, Phonological, Alexia

\section{INTRODUCTION}

The history of alexia as an acquired loss of reading, can be summarized around two essential standpoints [1,2]: 1891-1892 when Dejerine distinguished: "verbal blindness with agraphia" and "pure verbal blindness", and 1973 with Marshall and Newcombe published article on "patterns of paralexia: a psycholinguistic approach" [3]. Déjerine described clinical syndromes regularly related to topographical lesion using the anatomo-clinical method while Marshall \& Newcombe opened the era of the neurocognitive study of reading disorders. Thanks to the cognitive neuropsychology that alexia or acquired dyslexia can be explained using reading models that have taken a considerable expansion such as the dual route model or the connectionist framework $[4,5]$. These models involve distinct functional impairments resulting from the damage to left perisylvian cortex often results in impaired phonological processing, evident by speech sound errors (phonological paraphasias) and reduced performance on phonological awareness and manipulation tasks. This central phonological deficit also manifests in written language processing impairments known as phonological alexia and phonological agraphia syndromes characterized by disproportionate difficulty reading or spelling novel sequences of phonemes or graphemes (i.e., pseudowords) relative to real words which is the classical dissociation.

In terms of neuroimaging studies, an fMRI study [6] has been carried out to investigate the neural correlates of improved phonological processing in an individual with

\section{(巛)டคடロ}

Received: July 3, 2019

Revision: August 17, 2019

Accepted: August 19, 2019

Correspondence:

Mohamed Taiebine

Alzheimer's Center. Hay Nahda 2 GP Rue Beni Wariit. 10210. Rabat, Morocco

Tel: +212610665485

Fax: +212537759227

E-mail: taiebinemohamed@gmail.com
(C) 2019 The Korean Association of SpeechLanguage Pathologists

This is an Open Access article distributed under the terms of the Creative Commons Attribution NonCommercial License (http://creativecommons.org/ licenses/by-nc/4.0/) which permits unrestricted noncommercial use, distribution, and reproduction in any medium, provided the original work is properly cited. 
chronic aphasia and phonological alexia/agraphia before and after two phases of behavioral treatment. He made significant improvements in phonological skills and pseudoword reading after the first phase of treatment that were maintained following the second phase of treatment, so that the functional imaging results were expected to show the cortical areas associated with these gains. The residual language regions involved the activation of non-language regions within the dorsal attention network. However, according to the authors, it is not surprising that rehabilitation relied on these spared regions, as phonology relied on left hemisphere network and the pseudoword reading task was challenging in the face of damage to the dorsal language pathway.

Some authors [7-9] consider that phonological and deep dyslexia are variants of a single reading disorder rather than two separate entities. They explored this proposal as well as the nature of any continuum between these disorders, and the possible underlying bases of it. It is showed that many cases exhibited many of the symptoms associated with deep dyslexia whether or not they made semantic paralexias. Despite wide variation in word and nonword reading accuracy, there was considerable symptom overlap across these patients and, thus, no sensible dividing line to separate the participants into distinct groups.

Psycholinguistic studies in Arabic language regarding developmental dyslexia have been widely focusing on its theoretical-clinical aspects [10-14] and its therapeutics [15-17]. However, to our knowledge, few studies have been devoted to acquired dyslexia and most of them have been focused on singular case studies, given the rarity of such clinical presentation: deep alexia [18-21], alexia without agraphia [22]. Recently, cross-linguistic studies have been developed in nonEuropean languages [23]. In this context, psycholinguistic and neurolinguistic patterns of cases of phonological alexia have been described in Asian languages: in Japanese, Korean and Chinese.

Since the first description carried out by Beauvois and Derouesné [24], cases of phonological alexia have been studied in various Indo-European languages. But no cases have been reported in Arabic language as part of a neurolinguistic or a psycholinguistic study. We report a single case study of an Arabic speaking patient with a phonological alexia, following a wide left cerebral infarct.

Arabic belongs to a group of languages collectively known as the Semitic languages. Arabic and other Semitic languages generally have an idiosyncratic morphology whose main fea- ture is their nonlinear or nonconcatenative structure. Unlike English or Italian, Arabic morphemes are typically interwoven with each other in a way that makes borders difficult to distinguish between them [25]. Arabic is mainly consonantal language. It is written from the right to the left and is composed of 29 consonants and 8 vowels ( 3 short vowels, 3 long vowels and 2 diphthongs or glides). The majority of Arabic letters differ in their shapes depending on whether they appear at the beginning, middle or end of a word (allographes). The consonants are written as cursive characters whilst the vowels are written as diacritics attached to these cursive characters, above or below them. Arabic is considered as a deep orthographic system. One of the unique features of the Arabic orthography that differentiates it from many other alphabetical ones is the fact that most letters connect obligatorily to each other. Hence, these letters change their forms according to the location in the word (i.e., beginning, middle, or end), leading to the suggestion that connectivity adds a visual load which negatively impacts reading in Arabic [26]. Reading accuracy in Arabic requires vowelizing word endings according to their grammatical function in the sentence, which is an advanced phonological and syntactical ability. On the other hand, Arabic morphology is built of two types of structures: derivational (all words in Arabic are based on phonological patterns built on roots that are triconsonantal patterns and inflectional), while inflectional morphology is constructed by attaching prefixes and suffixes to real words. In addition to the consonant and vowel phoneme inventory of Arabic, there are also two phonemic processes, (1) vowel lengthening (as in kataba 'he wrote' $\rightarrow$ kaataba 'he corresponded') and (2) gemination, or doubling (tashdiid), as in darasa 'he studied' $\rightarrow$ darrasa 'he taught). Each of these processes contributes to the derivation of words from a lexical root and forms a key component of the derivational system of Arabic [27].

\section{METHODS}

The initial assessment of linguistic disorders is carried out with the Moroccan version of the Montreal-Toulouse linguistic protocol [22]. The qualitative description of results confirmed that the spontaneous speech of A.L is reduced; the lack of the word is important. The confrontational naming was impaired. Phonemic paraphasias and neologisms are observed while the grammar is respected. Auditory comprehension was preserved for simple words, however difficulties in understanding increased when it comes to syntactically complex sentences. 
Repetition was impaired for both words and sentences. The written language is characterized by a severe alexia.

Reading was assessed with the Arabic dyslexia dysgraphia Battery which consists of a corpus of 331 words and reading task of non-words. It includes different part of speech: Adjectives $(n=15)$ and nouns $(n=90)$ : nouns and adjectives are inflected according to masculine, singular and noun form. Verbs $(n=95)$ were derived from 8 triconsonantic roots. Some contain prefixes and infixes and others consist of inflection with suffixes. The verbs are inflected in third person, masculine, singular and past perfect form. Abstract words $(n=20)$ and concrete words $(n=20)$, are balanced in terms of frequency, gender, prefixation, length and the CV "consonant/ vowel" structure. Allographs $(n=76)$ contains a list of 76 verbs inflected in third person, the singular masculine and the past. The verbs are based on the triconsonantic roots that have a target letter in the initial, middle and final positions. The 7 target letters: ه ally dissimilar allographs. Functional words $(n=15)$ are 15 disyllabic functional words.

\section{CASE REPORT}

AL, 48 year old, right-handed man, who is a teacher of Arabic, at the age of 35 suffered from a hemiplegia with severe aphasia. A Cerebral Computed Tomography scan showed a wide left hemispheric infarct due to an internal carotid artery thrombosis. As a result, he developed a Broca's aphasia and an alexia. The patient was treated by a qualified speech-language pathologist in Arabic since the admission into the neurology department till his dismissal.

\section{Neurolinguistic assessment}

Before detailing the different parts of the speech assessed by the linguistic protocol using a corpus of 331 words, it is impor-

Table 1. Sample of writing the allograph $(\dot{\xi}$ lin different positions: initial, median and final

\begin{tabular}{|c|c|c|c|c|}
\hline $\begin{array}{l}\text { Type of } \\
\text { allograph }\end{array}$ & $\begin{array}{l}\text { Letter } \\
\text { Position }\end{array}$ & $\begin{array}{c}\text { Transcription } \\
\text { of the target } \\
\text { word }\end{array}$ & $\begin{array}{l}\text { Patient's } \\
\text { response }\end{array}$ & $\begin{array}{c}\text { Transcription } \\
\text { of the } \\
\text { patient's } \\
\text { response }\end{array}$ \\
\hline غَفَرَ & Initial & /gafara/ & غَفَرَ & /g̈afara/ \\
\hline شَغَلَ & Median & /şaġala/ & شَغَلَلَ & /şaġala/ \\
\hline بَلَغَ & Final & /balaġa/ & بَلَغَ & /balaġa/ \\
\hline
\end{tabular}

tant to detail the results of the pre-lexical assessment, then to compare the reading of 20 words vs. 20 non-words and finally to explore the reading of non-vocalized and vocalized texts in Arabic in our patient.

\section{Pre-lexical assessment}

This assessment gives us an initial reflection on the pre-lexical processes which are mainly visuo-spatial and visuo-attentional regarding Arabic letters and words. The experimental design of words was inspired from the list of 331 corpus which will be administered later. The patient did not display any impairment at the sub-lexical level: identification of letters (26/26 letters of Arabic correctly recognized). Then, the patient was asked to match each allograph which is the various graphic forms that a letter can have while keeping its position: isolated, initial, median or final. A sample of verbs and nouns

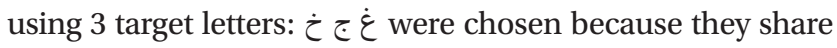
visually dissimilar allographs (Table 1). In another tasks, the patient was asked to recognize the letters which added to a simple word (verbs, adjectives and nouns) and find the missing letter in a word by selecting it from a proposed list according to its allographic aspects. However, in the lexical decision test, in which the patient was asked to decide whether a word is real or not when reading words/non-words (he produced 2 errors out of 30 responses).

\section{Reading 20 words vs. 20 non-words}

The words vs. non-words were generated from the subtest of reading in MT 86 [22]. The patient read correctly $95 \%$ of the words and $5 \%$ of the non-words. In reading, he mainly produces non-words (75\%). We found that in reading non-words, the patient produces phonemic paralexias (addition, substitution), lexicalizations and production of other non-words. The repetition of the same words and pseudo-words was spared (Table 2).

Table 2. Examples of error distribution in reading aloud non-words

\begin{tabular}{|c|c|c|c|c|}
\hline $\begin{array}{l}\text { Target } \\
\text { word }\end{array}$ & $\begin{array}{c}\text { Transcription } \\
\text { of the target } \\
\text { word }\end{array}$ & $\begin{array}{l}\text { Patient's } \\
\text { response }\end{array}$ & $\begin{array}{c}\text { Transcription } \\
\text { of the } \\
\text { patient's } \\
\text { response }\end{array}$ & Type of errors \\
\hline خَيُقِقُ & /xayoqun/ & خَوُقْ & /xawoqun/ & $\begin{array}{l}\text { Phonemic } \\
\text { substitution }\end{array}$ \\
\hline نَلَطًُ & /nalata/ & لَاطًَا & /lamalata/ & $\begin{array}{l}\text { Phonemic } \\
\text { substitution }\end{array}$ \\
\hline ضُغَرَبَ & /ḍ̆garaba/ & ضُو & /ḍo/ & Omission \\
\hline
\end{tabular}




\section{Corpus of 331 words}

Our patient produced 169 correct answers (51.05\%). The number of errors is 124 (37.46\%), while non-answers are 38

Table 3. Number and percentage of error's type in word reading in Arabic (corpus of 331 words)

\begin{tabular}{lcc}
\hline Type of errors & $\begin{array}{c}\text { Number of errors } \\
(\mathrm{n}=124)\end{array}$ & Percentage \\
\hline Morphological errors & 38 & 30.64 \\
Visual errors & 14 & 11.29 \\
Inversion & 3 & 2.41 \\
Omission & 9 & 7.25 \\
Addition & 4 & 3.22 \\
Substitution & 5 & 4.03 \\
Semiphonetics errors & 8 & 6.45 \\
Morphological semiphonetic & 42 & 33.87 \\
$\quad$ errors & & \\
Semantic nonmorphological & 1 & 0.80 \\
errors & &
\end{tabular}

Table 4. Correct responses and error distribution of different part of speech in word reading aloud using 331 corpus

\begin{tabular}{|c|c|c|c|c|c|c|}
\hline \multirow{2}{*}{$\begin{array}{l}\text { Part of speech } \\
\text { Response type }\end{array}$} & \multicolumn{2}{|c|}{$\begin{array}{c}\text { Correct } \\
\text { responses }\end{array}$} & \multicolumn{2}{|c|}{ No response } & \multicolumn{2}{|c|}{ Errors } \\
\hline & No & $\%$ & No & $\%$ & No & $\%$ \\
\hline Adjective & 10 & 66.6 & - & - & 5 & 33.3 \\
\hline Allographs & 27 & 35.52 & 6 & 7.89 & 43 & 56.57 \\
\hline Nouns (2 syllable) & 5 & 33.33 & 4 & 26.66 & 6 & 40 \\
\hline Nouns (3 syllable) & 11 & 73.33 & - & - & 4 & 26.66 \\
\hline Nouns $(H \mathrm{H}+\mathrm{p})$ & 19 & 95 & - & - & 1 & 5 \\
\hline Nouns (LH+p) & 14 & 70 & 3 & 15 & 3 & 15 \\
\hline Nouns (LL+p) & 15 & 75 & 1 & 5 & 4 & 20 \\
\hline Concrete nouns & 17 & 85 & 1 & 5 & 2 & 10 \\
\hline Abstract nouns & 17 & 85 & - & - & 3 & 15 \\
\hline Verbs+suffix & 12 & 37.5 & 5 & 15.62 & 15 & 46.86 \\
\hline Verbs+prefix & 3 & 10.71 & 11 & 39.28 & 14 & 50 \\
\hline $\begin{array}{l}\text { Verbs } \\
\text { (infinitive)+inflection }\end{array}$ & 3 & 37.5 & 1 & 12.5 & 4 & 50 \\
\hline $\begin{array}{l}\text { Verbs (infinitive)- } \\
\text { inflection }\end{array}$ & 8 & 44.44 & 1 & 6.66 & 6 & 40 \\
\hline Verbs+inflection+suffix & 3 & 33.33 & 1 & 11.11 & 5 & 55.55 \\
\hline $\begin{array}{r}\text { Verbs+prefix+ } \\
\text { germination }\end{array}$ & 1 & 12.5 & 2 & 25 & 5 & 62.5 \\
\hline $\begin{array}{l}\text { Verbs+prefix+ } \\
\text { germination+suffix }\end{array}$ & 2 & 16.66 & 3 & 25 & 7 & 58.33 \\
\hline Functors & 8 & 53.33 & - & - & 5 & 46.66 \\
\hline
\end{tabular}

representing (11.48\%). The errors interested different parts of speech: allographs, function words, adjectives, nouns and verbs (Tables 3 and 4). He displayed difficulties in reading non-words (90\%) but there was no semantic paralexia. The concrete and abstract words were both read successfully (85\%). The effect of grammatical class was shown by a better performance in reading names $(29.6 \%)$ than verbs $(8.87 \%)$ and functions (2.42\%). The particularity of this Arabic phonological alexia consists of the production of derivational errors (30.64\%) morphological semiphonetics errors (33.87\%) and visual errors (11.29\%).

It appeared that the patient has more difficulty reading the vocalized text (17 errors/88 words; $19 \%$ ) than the non-vocalized text (9 errors/47 words; 19\%). We observed the presence of an impairment in reading abstract words ( 7 errors/15; 46\%) more than the concrete words $(5 / 25 ; 20 \%)$. There was no grammatical class effect (Table 5 ).

Regarding the classification of paralexias as shown in the Table $6[18,28]$ we find that derivative $(n=38)$ and semipho-

Table 5. Reading vocalized vs non-vowelized text in Arabic (Montreal Toulouse Linguistic Protocol- MT86)

\begin{tabular}{|c|c|c|c|c|}
\hline \multirow{2}{*}{ Parts of speech } & \multicolumn{2}{|c|}{$\begin{array}{c}\text { Vowelized text } \\
\text { (number of words 88) }\end{array}$} & \multicolumn{2}{|c|}{$\begin{array}{l}\text { Non-Vowelized text } \\
\text { (number of words 47) }\end{array}$} \\
\hline & $\begin{array}{c}\text { Number of } \\
\text { errors }\end{array}$ & Percentage & $\begin{array}{c}\text { Number of } \\
\text { errors }\end{array}$ & Percentage \\
\hline Functions & $3 / 32$ & 9.3 & $3 / 18$ & 16.6 \\
\hline Abstract words & $7 / 15$ & 46.6 & $2 / 10$ & 20 \\
\hline Concrete words & $5 / 25$ & 20 & $0 / 7$ & - \\
\hline Adjectives & $1 / 7$ & 14.2 & $1 / 6$ & 16.6 \\
\hline Verbs & $1 / 9$ & 11.1 & $3 / 6$ & 50 \\
\hline
\end{tabular}

Table 6. Examples of the type of errors in reading 331 words according to the classification [28]

\begin{tabular}{|c|c|c|c|c|}
\hline $\begin{array}{l}\text { Target } \\
\text { word }\end{array}$ & $\begin{array}{c}\text { Transcription } \\
\text { of the target } \\
\text { word }\end{array}$ & $\begin{array}{l}\text { Patient's } \\
\text { response }\end{array}$ & $\begin{array}{l}\text { Transcription } \\
\text { of the patient's } \\
\text { response }\end{array}$ & Type of errors \\
\hline غَفَرَ & /gafara/ & غَفْورٌ & /gafūr'" & $\begin{array}{l}\text { Morphological or } \\
\text { derivational errors }\end{array}$ \\
\hline وِفَاقُ & /wifāqy & رِفَاقُ" & /rifāq" & Visual errors \\
\hline فَتَخَ & /fataḥa/ & فَتَحْع & /fatḥy & $\begin{array}{l}\text { Semiphonetic } \\
\text { errors }\end{array}$ \\
\hline أَنْتَتَ & /ānta/ & نْتَتَ & /nta/ & Omissions errors \\
\hline دَخَلْتُ & /dahaltu/ & دَخَلْنَنَّ & /dahaltunwa/ & Addition errors \\
\hline حَسَدَ & /hasada/ & حَسَنْ & /hasan` & Substitution errors \\
\hline
\end{tabular}


netic morphological ( $n=42)$ morphological errors are all sensitive to the root of the target word and not to the etymon.

Morphological or derivational errors: The patient's response was morphologically related to the target word and corresponds to its inflected or derived form. Morphological errors were semantically related to the stimulus [18]. Visual errors: The patient's response is a word visually and/or phonologically but neither semantically nor morphologically related to the stimulus. At least $50 \%$ of the letters (phonemes) of the answer are present in the stimulus. Semiphonetic errors: when the spelling of a word did not phonologically represent the target word due to lack of specific internal representation, semiphonetic errors may occur even when part of the phonoorthographic representation of the target word is preserved. These errors lead to omissions, additions and substitutions of phonemes. Omissions errors consist of a deletion of one or more phonemes of the target word. Addition errors which one or more phonemes are added to the target word. Substitution errors which some phonemes of the target word are replaced by others [28].

\section{DISCUSSION}

Our patient had a phonological alexia in which the mean features were:

- An impaired oral reading of pseudowords ( $90 \%$ of errors vs. 37\%) while reading real word is spared [24].

- This disorder is more explained by an impairment in the access to or disruption of representations within the phonological lexicon [29].

- No semantic paralexia, thus we can't report the diagnostic of deep Alexia.

- An effect of "part of speech," in which nouns (53\%) are better read than verbs and verbs (44\%) are better read than functors (33\%).

We note that phonological alexia in our patient is characterized by the production of derivational errors (30.6\%) semiphonetic morphological errors (33.8\%) and visual errors (11.2\%). On the other hand, there is no imagery effect, because concrete and abstract words are read with (15\%) errors. The patient hardly read the verbs with suffixes compared to those with prefixes and was better able to read frequent words compared to non-frequent ones. The explanation of the morphological errors in Arabic is given by the presence of the root effect of the word. When words are linked visually, phonetically and semantically, they have systematic morphological links. The predominance of morphological errors in Arabic is due to the semantico-morphological relations of words more present in Arabic than in other Western languages [18].

We believe that the effect of root plays a key role in reading of lexical words in Arabic and this explained the production of morphological errors which are more sensitive to the effect of the root than the etymon by our patient. The authors $[30,31]$ came to the same conclusion from the analysis of the paralexic errors of ZT, who is a bilingual Arabic-French patient with profound alexia, and whose the results support the state of the tri-consonantal root as being an abstract morphologico-lexical entity.

The status of the triconsonant root and its possible role in the Arabic mental lexicon has been assessed in the light of paralexia observed in the patient ZT with deep dyslexia who produced metathesis errors which aimed exclusively at the consonants within the root [31]. The fact that ZT metathesis errors did not involve the affixes (consonantal or vocalic) and epentetic segments, and have targeted the root specifically, suggests that the latter is morphologically and lexically the basic unit of the Arabic lexicon. ZT made metathesic errors where the underlying order of consonants was randomly disturbed. Although its overall deficit is the same in both languages, ZT does not produce such errors in French. It should be noted that his selective metathesis errors in Arabic target only the underlying consonants, while neither the affixes nor the epenthesis were objects to a metathesis. Thus, these results do not support the etymon theory.

In Bohas theory [32], if the etymon is the keystone organizing the lexical or morphemic unit, root-based metathesis errors should not occur since there is no level of representation similar to the root in the etymon. As a result, the authors assume that ZT's errors target morphemes that have more than one consonant, and if the etymon is indeed the basic unit of morphological representation, they should expect that metathesic errors are limited to the morphophonological domain corresponding to the etymon without involvement of the extensor. The results obtained from the errors of Z.T show that the etymon can neither replace nor be more important than the consonant root. While the root allows a general and simple characterization of metathesis errors by Z.T, the etymon can only explain a part of these errors [31]. The same observation can be applied to our patient $\mathrm{AL}$, whose root effect is the factor that induced the production of derivational morphological errors, which remains an argument in favor of the morphologico-semantic status of the word root and not the etymon. 
When the phonological decoding skills are not fully mastered and the morphology of the specific language is essential in word recognition [33], usually heavy reliance on the morphology may occur [18]. This fact explains the prevalence of morphological errors in the patient, when the phonological decoding process is partially functioning, in Arabic orthography words that are visually and phonologically similar and have a high potential of being related to the same root (root's effect). The semantic errors were low on average across all tasks. This is related to failure in phonological decoding and heavy reliance on visual orthography, which resulted in inaccurate phonological pronunciation.

By analyzing these different psycholinguistic effects, we notice that high-frequency words are better read than low-frequency words. Words with prefixes are better read than words with suffixes, in the absence of an effect of concreteness. Our results are consistent with the results of the Z.T patient [31]. Word patterns convey information that is syntactic and phonological in nature whereas roots convey semantic information. The consistent effects of roots by contrast to word patterns, suggest that the information conveyed by the root is critically used throughout processing while the one conveyed by the word pattern is transiently salient [34].

Since the first case of phonological alexia (LB) described in the literature [22], several authors have reported similar cases: RR [35] and RG, MO and IB [36]. The analysis of reading errors in these patients is characterized by the classic dichotomy between an inability to read non-words and difficulties in reading real words. Some authors have reported cases with an inability to read non-words while words are read without difficulty. These are typical cases of phonological alexia. In a systematic review of 38 published cases on phonological alexia [37], the author re-evaluated the validity of Friedman's criteria for distinguishing the two subtypes of alexia. According to its meta-analysis, $7 / 38$ cases (18.5\%) could be explained by a disturbance of phonological processing (a), 5/38 cases (13\%) could be explained by a deficiency of direct links between spelling and phonology (b), while the remaining cases (68.5\%) do not fit either of the two criteria. All these studies show that phonological alexia probably originates from different functional impairments. The presence or absence of a concomitant phonological deficiency is certainly a key element in the debate over the underlying deficit leading to phonological alexia.

Recently, phonological alexia has been investigated as a dysexecutive [38] impairment in FG, a case of 74-year-old right-handed patient with phonological alexia. The patient also has foreign accent syndrome and agraphia. FG presents a typical acquired phonological alexia that has never been reported before. He showed no phonological impairment, but his performance was weakened when he was asked to read non-words with contextual grapheme-to-phonemes conversion rules. This pattern of an impaired performance in specific non-word reading can be explained by the underlying executive dysfunction occurred during different lexical processes.

On the one hand, when we moved to non-alphabetic languages, we found that reading disorders in Japanese have been much more studied than other Asian languages. Japanese use two types of writing. Kanji uses Chinese characters which are purely semantic ideograms without phonological correspondence. In the usual writing, the roots of the words are written in Kanji. Any Japanese word can possibly be written in Kana. It has long been known that there are often dissociations between Kanji and Kana reading in Japanese aphasics. It seems that various similarities exist between Japanese and European cases [39].

On the other hand, phonological alexia has been described in the Korean language [40]. The patient group showed a relatively preserved orthographic and semantic processing ability although most of them were not able to perform on the phonological tasks. Significant differences between word and nonword reading aloud in patients indicated features of phonological alexia. The authors concluded that these results are consistent with previous studies on acquired phonological dyslexia, thus the neurolinguistic patterns in the Korean language were associated with the perisylvian language areas.

Finally, since our patient has no pre-lexical disorder and the classical dissociation in reading (words vs. non-words) is present as well as the effect of grammatical class and in absence of effect of concreteness or the production of semantic errors. This clinical picture is consistent with phonological alexia.

However, disregarding the presence of semantic paralexia, which will be the distinguishing feature of profound alexia, on the one hand, the neurological history of our patient is closer to a deep alexia (frontal cortical involvement of vascular origin with destruction of the language area) and on the other hand the typical linguistic pattern by the production of morphological errors instead of semantic errors can be explained by the potential participation of the right hemisphere in reading process in Arabic, whereas the alphabetic languages (English, French ...) do not present such peculiarity. The hypothe- 
sis of an involvement of the right hemisphere might pre-exist prior to the lesion and has the function of self-regulation of the lexical activity and once the left hemisphere is damaged, a release of the right hemisphere occurs which will limit the production of the semantic errors.

Some authors [7-9] pointed out that phonological and deep alexia are not separate clinical entities, but in fact they reflect a continuum through common errors in reading. This behavioral continuum was initially defined in terms of the severity of presence/absence of the "symptoms" of deep alexia. The ability to evaluate the concepts of a continuum of a phonological-deep alexia and the possible roles of phonological-semantic representations in explaining this acquired alexia is severely limited by the fact that current literature is dominated by unique case studies. In contrast, the role of semantic impairment in the explanation of surface alexia and other language tasks was confirmed by the adoption of case series design. While preserving the details of a single-case investigation, this approach allows direct comparisons between patients and thus exploration of qualitative and quantitative differences through case series studies.

\section{CONCLUSION}

Based on our patient's findings, we concluded that he has no pre-lexical disorder. We found the classical dissociation between an impaired reading of the non-words ( $90 \%$ of errors) and partial impairment in reading of real words, (37\% of errors). A grammatical class effect has also been found. There was no effect of concreteness or production of semantic paralexias; this clinical profile is consistent with phonological alexia [24].

The nature of errors produced by the patient reflects the uniqueness and complexity of the Arabic language. These errors are correlated with the morphological and semantic aspects of the root's word effect. The phenomenon of derivation and the presence or absence of grammatical markers (inflection, affixation) and diacritics, are crucial elements that determine a typical semantic and morphological access in reading words in Arabic.

According to the topography of lesion and neurolinguistic assessment (extended sylvian infarction, Broca aphasia then agrammatism), we expected a deep alexia, however, the patient did not produce any semantic paralexia. The possibility of a continuum between phonological and deep alexia has been discussed [7-9].
In a case study of pure alexia in Arabic language [22], the author hypothesized that reading in Arabic may require a bihemispheric participation besides the exclusive implication of the left hemisphere, as it is shown in different Western alphabetic languages. In this context, the Arabic script would require an additional visuo-spatial activity which is more sustained than consonantic processing in order to locate precisely the vowels, which are not integrated within the words, (above or below the consonants as diacritics). In addition, if the reader becomes proficient in reading Arabic texts, these later are no longer vowelized, as the reading relies more on lexico-semantic processing which is a lexical task undertaken by the right hemisphere. The role of diacritics in Arabic is quite similar to the ideogram script in Chinese which could be supplemented by an activation of the right hemisphere [41,42].

The implication of the right hemisphere in reading of Arabic words [22] as has been demonstrated by the magnetoencephalographic study [43], could be the factor that explain the absence of semantic paralexias in our patient. Recently [26], a study investigated the effects of the orthographic connectivity in Arabic on the time course of early brain electric responses during the visual word recognition using event-related potentials (ERPs). Reaction times variance was higher and accuracy was lower in nonconnected words ( $\mathrm{NCw}$ ) compared to fully connected $(\mathrm{Cw})$ words. ERPs analysis revealed significant amplitude and latency differences between $\mathrm{Cw}$ and $\mathrm{NCw}$ at posterior electrodes during the N170 component which implied the temporo-occipital areas dominantly in the left hemisphere which corroborate previous functional investigations (MEG, intra-cranial and MRI studies) and strengthens its role in orthographic processing. The authors showed that instead of slowing down reading, orthographic connectivity in Arabic skilled readers seems to impact positively the reading process already during the early stages of word recognition.

The data and the neurolinguistic analysis presented here in this case study showed some aspects of Arabic language. However, further research still needed using a larger dataset coupled with spatio-temporal functional neuroimaging explorations (fMRI, Diffusion Tensor Imaging [DTI], MEG, ERPs), collecting more subjects than just the single subject in this case study, and then conducting statistical analyses that compare the cohort to age-matched and healthy controls in order to reduce bias such as sample size and the inter and intra-individual variability which are commonly reported in contemporary aphasia research. 


\section{REFERENCES}

1. Déjerine J. Sur un cas de cécité verbale avec agraphie suivi d'autopsie. Mémoires de la Société de Biologie. 1891;3:197-201.

2. Dejerine J. Contribution à l'étude anatomopathologique et clinique des différents variétés de cécité verbale. Mémoires de la Société de Biologie. 1892;4:61-90.

3. Marshall JC, Newcombe F. Patterns of paralexia: A psycholinguistic approach. Journal of psycholinguistic research. 1973;2:175-199.

4. Coltheart M, Rastle K, Perry C, Langdon R, Ziegler J. DRC: a dual route cascaded model of visual word recognition and reading aloud. Psychological Review. 2001;108:204.

5. Seidenberg MS. Dyslexia in a computational model of word recognition in reading. InReading acquisition 2017;11:243-273.

6. DeMarco AT, Wilson SM, Rising K, Rapcsak SZ, Beeson PM. The neural substrates of improved phonological processing following successful treatment in a case of phonological alexia and agraphia. Neurocase. 2018;24:31-40.

7. Friedman RB. Recovery from deep alexia to phonological alexia: Points on a continuum. Brain and Language. 1996;52:114-128.

8. Crisp J, Lambon Ralph MA. Unlocking the nature of the phonological-deep dyslexia continuum: The keys to reading aloud are in phonology and semantics. Journal of Cognitive Neuroscience. 2006;18:348-362.

9. Crisp J, Howard D, Lambon Ralph MA. More evidence for a continuum between phonological and deep dyslexia: Novel data from three measures of direct orthography-to-phonology translation. Aphasiology. 2011;25:615-641.

10. Abu-Rabia S, Taha H. Phonological errors predominate in Arabic spelling across grades 1-9. Journal of Psycholinguistic Research. 2006;35:167.

11. Elbeheri G, Everatt J, Reid G, Mannai HA. Dyslexia assessment in Arabic. Journal of Research in Special Educational Needs. 2006;6: 143-152.

12. Friedmann N, Haddad-Hanna M. Letter position dyslexia in Arabic: from form to position. Behav Neurol. 2012;25:193-203.

13. Friedmann N, Haddad-Hanna M. Types of developmental dyslexia in Arabic. InHandbook of Arabic Literacy 2014 (pp. 119-151). Springer, Dordrecht.

14. Schiff R, Saiegh-Haddad E. When diglossia meets dyslexia: The effect of diglossia on voweled and unvoweled word reading among native Arabic-speaking dyslexic children. Reading and Writing. 2017;30:1089-1113.

15. Al Rowais F, Wald M, Wills G. An Arabic framework for dyslexia training tools. 1st International Conference on Technology for Helping People with Special Needs (ICTHP-2013), Saudi Arabia. pp. 63-68.

16. Aldabaybah B, Jusoh S. Usability Features for Arabic Assistive Technology for Dyslexia. In2018 9th IEEE Control and System Graduate Research Colloquium (ICSGRC) 2018 Aug 3 (pp. 223228). IEEE.

17. Layes S, Lalonde R, Rebai M. Effects of an Adaptive Phonological Training Program on Reading and Phonological Processing Skills in Arabic-Speaking Children With Dyslexia. Reading \& Writing Quarterly. 2019;35:103-117.

18. Béland R, Mimouni Z. Deep dyslexia in the two languages of an Arabic/French bilingual patient. Cognition. 2001;82:77-126.

19. Idrissi A, Kehayia E. Morphological units in the Arabic mental lexicon: Evidence from an individual with deep dyslexia. Brain and language. 2004;90:183-197.

20. Boumaraf A, Macoir J. The influence of visual word form in reading: single case study of an Arabic patient with deep dyslexia. Reading and Writing. 2016;29:137-158.

21. Boumaraf A, Macoir J. Orthographic connectivity in Arabic reading: a case study of an individual with deep dyslexia and letter-byletter reading. Neurocase. 2018;24:290-300.

22. El Alaoui-Faris M, Benbelaid F, Alaoui C, Tahiri L, Jiddane M, Amarti A, et al. Alexie sans agraphie en langue arabe: étude neurolinguistique et IRM. Revue neurologique. 1994;150:771-775.

23. Pugh K, Verhoeven L. Introduction to this special issue: Dyslexia across languages and writing systems. 2018.

24. Beauvois MF, Derouesne J. Phonological alexia: three dissociations. Journal of Neurology, Neurosurgery \& Psychiatry. 1979;42: 1115-1124.

25. Boudelaa S, Marslen-Wilson WD. Non-concatenative morphemes in language processing: Evidence from Modern Standard Arabic. InISCA Tutorial and Research Workshop (ITRW) on Spoken Word Access Processes 2000.

26. Taha H, Ibrahim R, Khateb A. How does Arabic orthographic connectivity modulate brain activity during visual word recognition: An ERP study. Brain Topography. 2013;26:292-302.

27. Ryding KC. Arabic: A linguistic introduction. Cambridge University Press; 2014 Mar 20.

28. Abu-Rabia S, Taha H. Reading and spelling error analysis of native. Reading and Writing. 2004;17:651-690.

29. Friedman RB. Two types of phonological alexia. Cortex. 1995;31: 397-403.

30. Prunet JF, Béland R, Idrissi A. The mental representation of Semitic words. Linguistic inquiry. 2000;31:609-648.

31. Idrissi A, Prunet JF, Béland R. Metathesis errors in aphasic speech: Implications for the status of abstract roots in Arabic. InBrain and Language 2002 Oct 1 (Vol. 83, No. 1, pp. 90-92). 525 B ST, STE 1900, SAN DIEGO, CA 92101-4495 USA: ACADEMIC PRESS INC ELSEVIER SCIENCE.

32. Bohas G, Dat M. Une théorie de l'organisation du lexique des langues sémitiques: matrices et étymons. Ens editions; 2007.

33. Abu-Rabia S, Share D, Mansour MS. Word recognition and basic cognitive processes among reading-disabled and normal readers in Arabic. Reading and Writing. 2003;16:423-442.

34. Boudelaa S, Marslen-Wilson W. The time-course of morphological, phonological and semantic processes in reading Modern Standard Arabic. InProceedings of the twenty-third annual conference of the cognitive science society 2001 Aug (p. 110). Edinburgh: Lawrence Erlbaum.

35. Bisiacchi PS, Cipolotti L, Denes G. Impairment in processing meaningless verbal material in several modalities: The relation- 
ship between short-term memory and phonological skills. The Quarterly Journal of Experimental Psychology. 1989;41:293-319.

36. Caccappolo-van Vliet E, Miozzo M, Stern Y. Phonological dyslexia without phonological impairment?. Cognitive Neuropsychology. 2004;21:820-839.

37. Tree JJ. Two types of phonological dyslexia-A contemporary review. Cortex. 2008;44:698-706.

38. Auclair-Ouellet N, Fossard M, St-Pierre MC, Macoir J. Toward an executive origin for acquired phonological dyslexia: A case of specific deficit of context-sensitive grapheme-to-phoneme conversion rules. Behavioural Neurology. 2013;26:171-173.

39. Sasanuma S. Phonological alexia in Japanese: A case study. Cog- nitive Neuropsychology. 1996;13:823-848.

40. Cho H, Pyun SB. Characteristics of acquired phonological dyslexia in Korean. Communication Sciences \& Disorders. 2015;20:570586.

41. Hoosain R. Psycholinguistic implications for linguistic relativity: A case study of Chinese. Psychology Press; 2013 Feb 1.

42. Coltheart M. The right hemisphere and disorders of reading. InFunctions of the right cerebral hemisphere. Academic Press London. 1983 Jan 1 (pp. 171-201).

43. Al-Hamouri F, Maestú F, del Río D, Fernández S, Campo P, Capilla A, et al. Brain dynamics of Arabic reading: A magnetoencephalographic study. NeuroReport. 2005;16:1861-1864. 